\title{
Management of infantile subglottic hemangioma: laser vaporization, submucous resection, intubation, or intralesional steroids?
}

\author{
L.J. Hoeve *, G.L.E. Küppers, C.D.A. Verwoerd \\ Department of Otorhinolaryngology, University Hospital Rotterdam-Sophia Children's Hospital, \\ Rotterdam, The Netherlands
}

Received 28 April 1997; received in revised form 27 September 1997; accepted 28 September 1997

\begin{abstract}
The infantile subglottic hemangioma can be treated in various ways. The results of the treatment used in the Sophia Children's Hospital, intralesional steroids and intubation $(\mathrm{IS}+\mathrm{I})$, are discussed and compared with the results of other current treatment methods: $\mathrm{CO}_{2}$ laser vaporization, submucous resection and intubation alone. A total of 18 infants were treated for subglottic hemangioma in our hospital: ten with IS + I alone, five were first treated with systemic therapy and later with IS + I alone and three with various therapies. IS + I was effective in 14 of the 15 patients, one patient was lost from follow up. The remaining three infants were treated with (combinations of) various therapies, because IS + I failed or was not tried. Two patients were finally cured, one still has a tracheotomy. Of other current therapies, $\mathrm{CO}_{2}$ laser vaporization is reported to be effective. In all $30 \%$ of the infants treated in Boston Children's Hospital with $\mathrm{CO}_{2}$ laser needed a tracheotomy. Moreover subglottic stenosis is a serious complication. Submucous resection is often successful. It may be complicated by subglottic stenosis and in some cases, depending on the localization of the hemangioma, it may be contraindicated. Intubation alone is less effective than intubation combined with intralesional steroids. Management of subglottic hemangioma in Sophia Children's Hospital is primarily intralesional steroids and intubation and secondarily submucous resection or tracheotomy. $\mathrm{CO}_{2}$ laser vaporization is seldom applied because of the risk of subglottic stenosis. (C) 1997 Published by Elsevier Science Ireland Ltd.
\end{abstract}

* Corresponding author. Tel.: + 3110 4636073; fax: + 31104636472.

0165-5876/97/\$17.00 (C) 1997 Published by Elsevier Science Ireland Ltd. All rights reserved.

PII S0165-5876(97)00144-4 
Keywords: Infantile subglottic hemangioma; Laser; Resection; Intubation; Intralesional steroids

\section{Introduction}

A subglottic hemangioma is a benign tumor which spontaneously goes into regression during infancy. It usually presents with symptoms of respiratory tract obstruction in the first months of life. The male to female ratio is reported to be 1:2 $[2,22]$. Histologically, most hemangiomas are capillary $(91.6 \%)$, the others are cavernous or mixed [21]. The diagnosis is made on the endoscopic appearance of the tumor and may be confirmed by biopsy. Most hemangiomas are confined to the subglottis, extralaryngeal extension will be revealed by magnetic resonance imaging.

A great variety of therapies and, in many instances combinations of therapies, have been applied: 'wait and see' with or without tracheotomy [6,18] systemic steroids [4,10] interferon [16,23], short-term intubation [15], $\mathrm{CO}_{2}$ (or other) laser $[11,22]$, open surgical approach and submucous resection [7,14,17,20,19,24], intralesional steroids with short-term intubation, developed in the Sophia Children's Hospital [13] and other therapies [1].

'Wait and see' can only be employed for hemangiomas with minor symptoms. A tracheotomy does not influence the natural course of the hemangioma and thus has to remain in place possibly for several years. Moreover a tracheotomy has considerable consequences for general and speech development, is associated with respiratory tract infections and has a mortality rate of $1-2 \%$ [8]. Systemic steroids have a (limited) effect on the airway obstruction and, if given for a long period, serious side effects: growth retardation, Cushing syndrome and immune deficiency. Their value lies in their use as an additional therapy. Interferon has reportedly a beneficial effect, but its working mechanism and indications are yet to be defined.

The more effective or established therapies are $\mathrm{CO}_{2}$ laser vaporization, submucous resection, short-term intubation and intralesional steroids followed by shortterm intubation.

The present report aims to evaluate the method used in the Sophia Children's Hospital, intralesional steroids and intubation and to compare this method with three current therapies employed in other institutions: $\mathrm{CO}_{2}$ laser, resection and intubation. Finally a therapeutic approach of the subglottic hemangioma is formulated, based upon our results and the findings reported in the literature.

\section{Patients and methods}

The records of all patients treated for subglottic hemangioma in the Sophia Children's Hospital from 1982 to 1997 were studied retrospectively. The treatment policy during that period included in most patients intralesional injection of steroids, followed by one week intubation (IS + I). Treatment was only employed if 


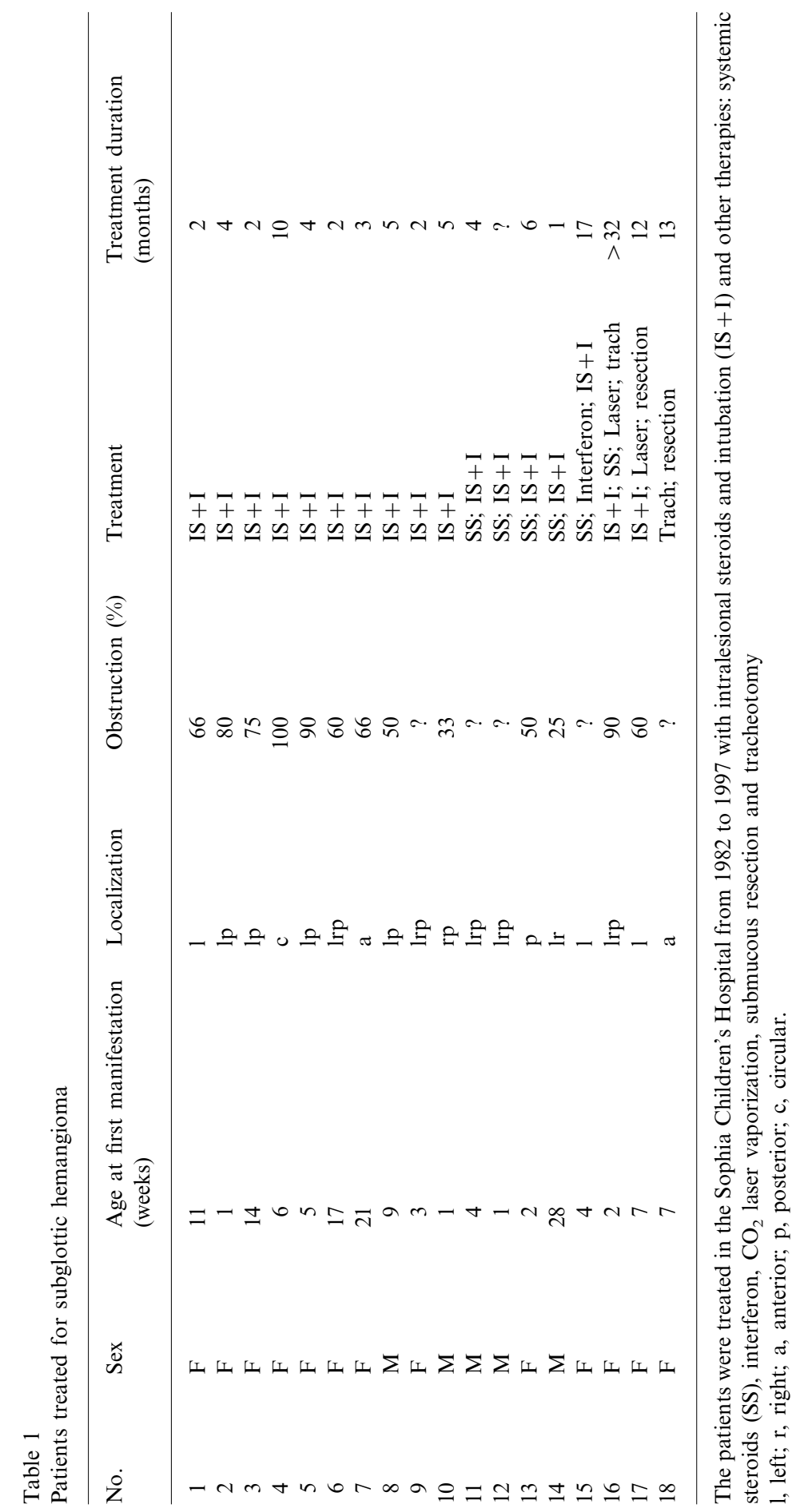


serious symptoms of airway obstruction were present. Approximately $60 \mathrm{mg}$ methylprednisolone was administered into the lesion, a spillage of a few $\mathrm{mg}$ was usually unavoidable. The treatment was repeated when symptoms of severe obstruction recurred. If that happened within 4 weeks, the patients were intubated but they received no steroids to avoid overdose. The treatment method was extensively described in an earlier report [13].

In all, 18 infants (13 girls and five boys) with subglottic hemangioma were treated in our hospital, either primarily or after treatment elsewhere and referral. The age at first manifestation of the symptoms, the localization and size of the tumor and its treatment are presented in Table 1. Criteria for the diagnosis were the endoscopic aspect, localization and firmness of the tumor. Biopsies were obtained only in a minority of the cases. The percentage of obstruction was visually estimated on endoscopy. Approximately half of the infants also had cutaneous hemangioma.

A total of ten patients were treated with IS + I alone. Some five others were first treated elsewhere with systemic steroids or interferon, but were referred to our hospital when signs of airway obstruction recurred. Systemic treatment was discontinued and replaced by IS + I. Another patient was treated with IS + I, systemic steroids, laser surgery and finally a tracheotomy. There was one patient that had IS + I, laser surgery and finally a laryngofissure and submucosal resection of the hemangioma. An infant underwent a tracheotomy followed by submucous resection for a subglottic stenosis. The tissue responsible for the stenosis was resected and appeared to be a hemangioma at histologic examination.

Treatment was called a success if from the moment of its termination no serious symptoms of obstruction (re)occurred.

The results of IS + I in Sophia Children's Hospital are compared to the results of various therapies reported from other hospitals.

\section{Results}

The results of the therapies employed in the Sophia Children's Hospital are shown in Table 2. An unobstructed airway was achieved in all ten patients treated

Table 2

Treatment results in Sophia Children's Hospital; IS + I only and various therapies in combination with IS + I

\begin{tabular}{lrrll}
\hline Treatment & $N$ & $N$ cured & $\begin{array}{l}\text { Mean age when cured } \\
\text { (months) }\end{array}$ & Mean follow up (years) \\
\hline IS + I & 10 & 10 & $8(4-14)$ & $8(9 / 12-13)$ \\
SS; (Interf); IS + I & 5 & 4 & $13(6-20)$ & $5(2-10)$ (no follow up in 1) \\
IS + I; SS; laser; trach. & 1 & 0 & - & Tracheotomy \\
IS + I; laser; resection & 1 & 1 & 14 & 2 \\
Trach; resection & 1 & 1 & 15 & 6 \\
\hline
\end{tabular}


Table 3

Treatment in Sophia Children's Hospital; IS + I in 14 cured patients and in three patients in which IS + I was without success

\begin{tabular}{lcc}
\hline & Cured (14) & Not cured (3) \\
\hline Number of injections & $3(1-12)$ & $5(2-11)$ \\
Number endoscopies and intubations & $6(1-20)$ & $8(3-16)$ \\
Days intubated & $37(6-129)$ & $54(20-93)$ \\
Duration of treatment (months) & $5(1-12)$ & $5(1-9)$ \\
Age at last treatment (months) & $9.5(4-20)$ & $11(8-14)$ \\
\hline
\end{tabular}

with IS + I only, at ages between 4 and 14 months (mean 8 months). Four of five patients in whom the systemic treatment was replaced by IS $+\mathrm{I}$, had a patent airway at ages between 6 and 20 (mean 13) months. The remaining patient went for further treatment elsewhere and was lost from follow up.

IS + I was unsuccessful in two infants. One was given a tracheotomy at 14 months, the other was successfully treated with a submucous resection at 12 months of age. The policy of IS + I was effective in 14 of 17 patients $(82 \%)$.

Systemic side effects of intralesionally administered steroids such as growth retardation or Cushing syndrome were not seen. Some infants showed laryngeal granulations, or suffered from lower airway infections during the intubation. None of the patients developed subglottic stenosis.

Table 3 shows what IS + I involved for the patients in terms of number of injections, intubations and duration of therapy. A mean number of six endoscopies in general anesthesia followed by six periods (37 days) of intubation were needed in the infants treated with success. After a treatment period which lasted a mean 5 months (range 1-12), a permanently patent airway was achieved at a mean age of 9.5 months (range $4-20$ ).

The follow up periods vary between 9 months and more than 13 years. One patient is still dependent on a tracheotomy at 3 years of age, a second was lost from follow up. All others have an unobstructed airway and develop normally.

\section{Discussion}

The natural course of an infantile cutaneous hemangioma consists of rapid growth during the first year of life, followed by a slow involution that may last 5-7 years $[3,9,25]$. The study of the natural course of a subglottic hemangioma is impeded by the need for intervention, but most authors agree that it shows a similarly rapid growth until $6-12$ months of age [12,15], followed by involution after 18 or more months $[6,15,19]$. Patients treated by Sebastian with a tracheotomy only, could be decannulated at an average age of 17 months [18].

Consequently, treatment of subglottic hemangioma should aim, first at maintaining a patent airway during the first years of life and second, if possible, at shortening the natural course of the tumor. Therapies that may involve serious side 
effects, such as subglottic stenosis, or delay in speech and general development, should possibly be avoided.

A total of four established therapies are compared for their efficacy and side effects: $\mathrm{CO}_{2}$ laser vaporization, submucous resection, short-term intubation and intralesional steroids followed by intubation. The results are shown in Table 4.

In all 28 infants treated for subglottic hemangioma with $\mathrm{CO}_{2}$ laser vaporization at the Boston Children's Hospital, a patent airway was achieved by 3 years of age or earlier. Besides $\mathrm{CO}_{2}$ laser treatment most patients also received systemic steroids. Five patients were referred with a tracheotomy and seven $(30 \%)$ more of the remaining 23 infants needed one during the treatment. Subglottic stenosis complicated the treatment in five infants (18\%) [22]. $\mathrm{CO}_{2}$ laser treatment, although effective, appears to have a high risk for stenosis [5] and in many patients a tracheotomy cannot be avoided.

Submucous resection has been successful in several reported cases. A tracheotomy may be avoided or is only needed for a short period. A subglottic stenosis following a resection was reported by Wiatrak [24]. Extension into the glottis or deep into the trachea are relative contraindications [7,14,17,19,20,24].

The treatment reported by Narcy, intubation for 10 days after systemic steroids had failed, cured ten of 16 patients $(63 \%)$. Of these 16 infants four needed a tracheotomy [15]. Intubation alone appears less effective than intubation plus intralesional steroids.

The treatment of first choice in the Sophia Children's Hospital, intralesional steroids and short-term intubation, achieved in $82 \%$ of the patients a permanently patent airway at a mean 9.5 months of age. With this approach only one infant $(6 \%)$, in which IS + I failed, needed a long-term tracheotomy and subglottic stenosis did not occur. The side effects were limited: respiratory tract infections caused by the intubation and repeated hospitalizations. Some infants had many endoscopies and were intubated for a rather long total period.

Table 4

Comparison of four current treatment methods in various institutions: $\mathrm{CO}_{2}$ laser [22] resection [24], intubation [15], IS + I [this report]

\begin{tabular}{llll}
\hline & $\begin{array}{l}\text { Tracheotomy necessary } \\
\text { during treatment }(\%)\end{array}$ & $\begin{array}{l}\text { Treatment } \\
\text { complicated by } \\
\text { stenosis }(\%)\end{array}$ & $\begin{array}{l}\text { Patients }(\%) \text { with a } \\
\text { patent airway }\end{array}$ \\
\hline $\mathrm{CO}_{2}$ laser $(n=28)$ & 30 & 18 & 100 at $<3$ years. \\
Resection $(n=19)$ & 53 & 5 & 95 at 10 months. (mean) \\
Intubation $(n=16)$ & 25 & 6 & 63 at \pm 1 year \\
IS + I $(n=18)$ & 6 & 0 & 82 at 9.5 months. (mean)
\end{tabular}

Criteria: tracheotomy necessary during treatment, treatment complicated by stenosis and age when patent airway. 


\section{Conclusion}

Management of infantile subglottic hemangioma in our hospital implies intralesional steroids followed by intubation. Contrary to former years now the number of intubation periods are usually limited to two or three. The second choice treatment is submucous resection, or if that operation is contra-indicated, a tracheotomy. Systemic steroids (and maybe interferon in future) can be used as an additional therapy for short periods. We seldom apply $\mathrm{CO}_{2}$ laser vaporization, as the risk for subglottic stenosis is considered too high.

\section{References}

[1] B. Benjamin, P. Carter, Congenital laryngeal hemangioma, Ann. Otolaryngol. Rhinol. Laryngol. 92 (1983) $448-455$.

[2] L. Brodsky, N. Yoshpe, R.J. Ruben, Clinical-pathological correlates of congenital subglottic hemangiomas, Ann. Otolaryngol. Rhinol. Laryngol. 92 (1983) 4-18.

[3] D.I. Choa, M.C.F. Smith, J.N.G. Evans, C.M. Bailey, Subglottis haemangioma in children, J. Laryngol. Otolaryngol. 100 (1986) 447-454.

[4] S.R. Cohen, C. Wang, Steroid treatment of hemangioma of the head and neck in children, Ann. Otolaryngol. Rhinol. Laryngol. 81 (1972) 584-590.

[5] R.T. Cotton, T.L. Tewfik, Laryngeal stenosis following carbon dioxide laser in subglottic hemangioma. Report of three cases, Ann. Otolaryngol. Rhinol. Laryngol. 94 (1985) 494-497.

[6] S.S. Feuerstein, Subglottic hemangioma in infants, Laryngoscope 83 (1973) 466-475.

[7] P. Froehlich, D. Stamm, D. Floret, A. Morgon, Management of subglottic haemangioma, Clin. Otolaryngol. 20 (1995) 336-339.

[8] G.J. Gianoli, R.H. Miller, J.L. Guarisco, Tracheotomy in the first year of life, Ann. Otolaryngol. Rhinol. Laryngol. 99 (1990) 896-901.

[9] M.M. Goldsmith, G.L. Strope, D.S. Postma, Presentation and management of postcricoid hemangiomata in infancy, Laryngoscope 97 (1987) 851-853.

[10] D.B. Hawkins, D.M. Crockett, et al., Corticosteroid management of airway hemangiomas: longterm follow-up, Laryngoscope 84 (1984) 633-637.

[11] G. Healy, T. McGill, E.M. Friedman, Carbon dioxide laser in subglottic hemangioma: an update, Ann. Otolaryngol. Rhinol. Laryngol. 93 (1984) 370-373.

[12] P.H. Holinger, Clinical aspects of congenital anomalies of the larynx, trachea, bronchi and oesophagus: semon lecture, J. Laryngol. Otolaryngol. 75 (1961) 1-44.

[13] J. Meeuwis, C.E. Bos, L.J. Hoeve, E. Van der Voort, Subglottic hemangiomas in infants: treatment with intralesional corticosteroid injection and intubation, Int. J. Pediatr. Otorhinolaryngol. 19 (1990) 145-150.

[14] J.J.S. Mulder, P. Van den Broek, Surgical treatment of infantile subglottic hemangioma, Int. J. Pediatr. Otorhinolaryngol. 17 (1989) 57-63.

[15] P. Narcy, P. Contencin, S. Bobin, Y. Manac'h, Treatment of infantile subglottic hemangioma. A report of 49 cases, Int. J. Pediatr. Otorhinolaryngol. 9 (1985) 157-164.

[16] L.A. Ohlms, D.T. Jones, T.J. McGill, G.B. Healy, Interferon alfa-2a therapy for airway hemangiomas, Ann. Otolaryngol. Rhinol. Laryngol. 103 (1994) 1-8.

[17] Y. Sakakura, M. Ohi, S. Yamada, Y. Miyoshi, A case of subglottic hemangioma: a new technique of surgical removal, Auris. Nasus. Larynx. 7 (1980) 81-88.

[18] B. Sebastian, O. Kleinsasser, Zur Behandlung der Kehlkopfhämangiome bei Kindern, Laryngol. Rhinol. Otolaryngol. 63 (1984) 403-407.

[19] A.B. Seid, S.M. Pransky, D.B. Kearns, The open surgical approach to subglottic hemangioma, Int. J. Pediatr. Otorhinolaryngol. 22 (1991) 85-90. 
[20] H.S. Sharp, Hemangioma of the trachea in an infant, successful removal, J. Laryngol. Otolaryngol. 63 (1949) 413-414.

[21] A.H. Shikhani, M.M. Jones, B.R. Marsh, M.J. Holliday, Infantile subglottic hemangiomas: an update, Ann. Otolaryngol. Rhinol. Laryngol. 95 (1986) 336-347.

[22] K.C.Y. Sie, T. McGill, G.B. Healy, Subglottic hemangioma: ten year's experience with the carbon dioxide laser, Ann. Otolaryngol. Rhinol. Laryngol. 103 (1994) 167-172.

[23] B. Soumekh, G.L. Adams, R.S. Shapiro, Treatment of head and neck hemangiomas with recombinant interferon alpha 2B, Ann. Otolaryngol. Rhinol. Laryngol. 105 (1996) 201-206.

[24] B.J. Wiatrak, J.S. Reilly, A.B. Seid, S.M. Pransky, J.V. Castillo, Open surgical excision of subglottic hemangioma in children, Int. J. Pediatr. Otorhinolaryngol. 34 (1996) 191-206.

[25] H.E. Willshaw, J.P. Deady, Vascular hamartomas in childhood, J. Pediatr. Surg. 22 (1987) $281-283$. 